\title{
PARA ALÉM DA DICOTOMIA ENTRE TRABALHO DECENTE E TRABALHO DIGNO: reconhecimento e direitos humanos
}

\author{
Cinara L. Rosenfield \\ Jandir Pauli**
}

\begin{abstract}
O objetivo deste estudo é realizar uma discussão teórico-conceitual das noções de trabalho decente e trabalho digno, a partir da contraposição conceitual entre cidadania e direitos humanos. $\mathrm{O}$ argumento deste artigo é que trabalho decente remeteria à noção de cidadania e a uma concepção operacional, claramente apontada na agenda da Organização Internacional do Trabalho (OIT), enquanto o trabalho digno remete à Declaração Universal dos Direitos Humanos (DUDH) e é dependente de uma rede de direitos. A fim de transpor essa dicotomia, propomos uma visão integral do ser humano no trabalho, através da noção de reconhecimento e de uma abordagem holística dos direitos humanos que integra a noçẫo de trabalho decente.

PALAVRAS-CHAVE: trabalho decente, trabalho digno, direitos humanos, visão integral dos direitos, reconhecimento.
\end{abstract}

\section{BREVE CONTEXTUALIZAÇÃO: direitos huma- nos e trabalho}

A Declaração Universal dos Direitos Humanos de 1948 (DUDH) inaugura um código de ética universal para a reafirmação da dignidade humana. Reafirma porque a Declaração surgiu em um contexto marcado pelo horror ao extermínio praticado nos campos de concentração nazistas que rompeu com o paradigma jusnaturalista, segundo o qual os direitos humanos são naturais e anteriores à própria lei. A Declaração alargou o conceito de dignidade humana, estabelecendo os Direitos Econômicos, Sociais e Culturais (DHESC), ao lado e articulados aos já estabelecidos direitos civis e políticos.

Se a $2^{\text {a }}$ Guerra significou a ruptura com os direitos humanos, o Pós-Guerra deveria significar a sua reconstrução.

* Doutora em Sociologia. Professora do Programa de PósGraduação de Sociologia da Universidade Federal do Rio Grande do Sul - UFRGS.

Av. Bento Gonçalves, 9500 - Prédio 43311, Agronomia. Cep: 91509-900 - Porto Alegre - Rio Grande do Sul Brasil.rosenfield@uol.com.br

** Doutor em Sociologia. Professor da Faculdade Meridional (IMED). jandir@imed.edu.br
Neste sentido, em 10 de dezembro de 1948, é aprovada a Declaração Universal dos Direitos Humanos, como marco maior do processo de reconstrução dos direitos humanos. Introduz ela a concepção contemporânea de direitos humanos, caracterizada pela universalidade e indivisibilidade destes direitos. Universalidade porque clama pela extensão universal dos direitos humanos, sob a crença de que a condição de pessoa é o requisito único para a dignidade e titularidade de direitos. Indivisibilidade porque a garantia dos direitos civis e políticos é condição para a observância dos direitos sociais, econômicos e culturais e vice-versa. Quando um deles é violado, os demais também o são. Os direitos humanos compõem assim uma unidade indivisível, interdependente e inter-relacionada (Piovesan, 2000, p.94- 95).

A Declaração de Viena de 1993 reitera, no seu artigo $5^{\circ}$, que "Todos os direitos humanos são universais, indivisíveis interdependentes e interrelacionados. A comunidade internacional deve tratar os direitos humanos de forma global, justa e equitativa, em pé de igualdade e com a mesma ênfase" (ONU, 1993), de maneira que as noções de interdependência e inter-relação dos direitos humanos reforçam a associação entre os direitos civis e políticos e os direitos humanos econômi- 
cos, sociais e culturais (DHESC).

Em termos políticos, a DUDH associou o discurso liberal da cidadania com o discurso social, de forma a articular tanto direitos civis e políticos (arts.3 e 21), quanto direitos sociais, econômicos e culturais (arts.22 e 28), percebidos como direitos fundamentais. Essa perspectiva é ratificada no Pacto Internacional sobre os Direitos Econômicos, Sociais e Culturais (PIDESC) da Assembleia Geral da ONU de 1966, na Proclamação de Teerã de 1968, na Resolução da Assembleia Geral de 1977, e no Protocolo Adicional à Convenção Americana sobre os Direitos Econômicos, Sociais e Culturais, conhecido como Protocolo de São Salvador, de 1988. De certa forma, tal concepção rompe com as declarações anteriores e inaugura o reconhecimento da dimensão coletiva dos direitos, estabelecendo uma reciprocidade entre direitos formais como a liberdade e a base econômica adequada para o seu exercício.

É mister lembrar ainda que, desde a sua promulgação, a DUDH tenta construir um "Direito Internacional dos Direitos Humanos” com força jurídica vinculante (Piovesan, 2004, p. 48). De fato, após a declaração de 48, iniciou-se um processo de "jurisdicização" finalizado em 1966 com o Pacto Internacional dos Direitos Civis e Políticos e o Pacto Internacional dos Direitos Econômicos, Sociais e Culturais (PIDESC).

O Brasil se insere nesse contexto internacional a partir do processo de redemocratização.

No caso brasileiro, o processo de incorporação do Direito Internacional dos Direitos Humanos e de seus importantes instrumentos é consequência do processo de democratização, iniciado em 1985.

O marco inicial do processo de incorporação de tratados internacionais de direitos humanos pelo Direito Brasileiro foi a ratificação, em 1989, da Convenção contra a Tortura e Outros Tratamentos Cruéis, Desumanos ou Degradantes. A partir desta ratificação, inúmeros outros importantes instrumentos internacionais de proteção dos direitos humanos foram também incorporados pelo Direito Brasileiro, sob a égide da Constituição Federal de 1988. Assim, a partir da Carta de 1988, foram ratificados pelo Brasil: a) a Convenção Interamericana para Prevenir e Punir a Tortura, em 20 de julho de 1989; b) a Convenção sobre os
Direitos da Criança, em 24 de setembro de 1990; c) o Pacto Internacional dos Direitos Civis e Políticos, em 24 de janeiro de 1992; d) o Pacto Internacional dos Direitos Econômicos, Sociais e Culturais, em 24 de janeiro de 1992; e) a Convenção Americana de Direitos Humanos, em 25 de setembro de 1992; f) a Convenção Interamericana para Prevenir, Punir e Erradicar a Violência contra a Mulher, em 27 de novembro de 1995. (Piovesan, 2000, p.100-101)

O Brasil aderiu, pois, ao PIDESC em 24 de janeiro de 1992 e, em 1996, lançou seu $1^{\circ}$ Programa Nacional de Direitos Humanos, que continha basicamente direitos civis e políticos. Foi apenas no $2^{\circ}$ Programa que os direitos sociais, econômicos e culturais foram contemplados. Segundo Abramovich (2006), a adscrição de um direito ao catálogo de direitos civis e políticos, ou de direitos econômicos, sociais e culturais, tem um valor heurístico, ordenador, classificatório. Contudo, em se tratando de análise teórica, a conceituação rigorosa remeteria a um "continuum de direitos, no qual o espaço de cada direito estaria determinado pelo peso simbólico do componente de obrigações positivas ou negativas nele delineadas.” (Abramovich, 2006, p.194). Entenda-se por obrigações positivas aquelas que necessitam da ação governamental para sua efetivação; e por negativas aquelas que devem ser garantidas pela sua afirmação.

A tradição moderna, de Smith a Marx, reconhece a centralidade do trabalho e sua qualificação como espaço da interação do ser humano com o meio em que vive, seja em termos naturais ou sociais. E essa continua sendo a exigência fundamental da economia política do trabalho no século XXI: a produção de uma economia que universalize o direito ao trabalho como um direito humano fundamental. É com esse objetivo que, do art. $6^{\circ}$ ao $9^{\circ}$, o PIDESC afirma que o direito ao trabalho consiste:

No recebimento de remuneração justa e equitativa entre homens e mulheres, capaz de garantir condições de existência digna aos trabalhadores (as) e suas famílias; condições de trabalho seguras e higiênicas; lazer, jornada de trabalho razoável, descanso e férias remuneradas, além do direito de associar-se e de filiar-se a sindicatos, de realizar greves, e de ter assegurada a previdência social (Costa; Arantes, 2009, p. 23). 
Essa é a compreensão também expressa nas conclusões da Observação Geral 18 do Comitê DHESC da ONU:

O direito ao trabalho é essencial para a realização de outros direitos humanos e constitui uma parte inseparável e inerente da dignidade humana. Toda pessoa tem o direito a trabalhar para poder viver com dignidade. $\mathrm{O}$ direito ao trabalho serve, ao mesmo tempo, à sobrevivência do indivíduo e de sua família e contribui também, na medida em que o trabalho é livremente escolhido e aceito, para a sua plena realização e o seu reconhecimento no seio da comunidade (Le Droit..., 2005, p.2 ).

Os direitos de trabalho abrangidos pelo PIDESC incluem, entre outros, o direito ao trabalho livremente escolhido, ao pleno emprego, a salários justos, a um padrão de vida adequado, a condições de segurança e de trabalho saudável, ao descanso e lazer, a formar e aderir a sindicatos, além do direito à greve e à segurança social. Esses direitos do trabalho do PIDESC coincidem com os pilares da Agenda do Trabalho Decente da Organização Internacional do Trabalho (OIT), bem como com os direitos nas convenções da OIT, a saber: a) respeito às normas internacionais do trabalho, em especial aos princípios e direitos fundamentais do trabalho (liberdade sindical e reconhecimento efetivo do direito de negociação coletiva; eliminação de todas as formas de trabalho forçado; abolição efetiva do trabalho infantil; eliminação de todas as formas de discriminação em matéria de emprego e ocupação); b) promoção do emprego de qualidade; c) extensão da proteção social; d) diálogo social (Brasil, 2010).

\section{CIDADANIA E DIREITOS HUMANOS: o concei- to de dignidade}

A concepção de cidadania e a noção de direitos humanos, embora complementares, remetem a sentidos distintos.

Seguindo Benevides [1997?], a cidadania e os direitos de cidadania estariam atrelados a uma determinada ordem jurídico-política de um país,
Estado ou Constituição. Seu caráter político opõese à ideia de um valor universal. No entanto, apesar dessa distinção conceitual, é frequente que os direitos do cidadão coincidam com os direitos humanos, de natureza universal e válidos permanentemente. Os direitos humanos são universais e naturais. Assim, enquanto a cidadania refere-se a um membro de uma sociedade política, a um membro de um Estado, os direitos humanos referem à pessoa humana na sua universalidade. São naturais porque existem antes de qualquer lei, e não precisam estar especificados numa lei para serem exigidos, reconhecidos, protegidos e promovidos. Além de universais e naturais, os direitos humanos são históricos, pois suscetíveis de transformação ao longo do tempo e em diferentes espaços políticos e culturais. Mas como os direitos humanos seriam simultaneamente universais e históricos?

Essa aparente contradição revela a tensão existente

[...] em torno do conceito de dignidade humana, a saber, i) a tensão entre seu caráter natural e seu caráter artificial; ii) a tensão entre seu caráter abstrato e seu caráter concreto e iii) a tensão entre seu caráter universal e seu caráter particular (Monsalve; Román, 2009, p.42).

A tensão entre o caráter natural ou consensual da dignidade refere-se à contraposição entre a noção de dignidade como elemento definidor da ideia de natureza humana (independentemente dos pertencimentos sociais, étnicos, religiosos, de gênero etc.) e a noção de dignidade como uma característica "artificial", atribuída consensualmente aos seres humanos com fins utilitários. Artificial no sentido de se constituir como um pacto social em torno da dignidade a ser respeitada.

A tensão entre o caráter abstrato ou concreto da dignidade se refere ao grau de abstração (e, portanto, sem conteúdo prático) ou, ao contrário, de concreção (relacionado de maneira concreta a aspectos da vida humana que remetem a direitos a serem preservados).

[...] por trás da ideia de dignidade humana está a ideia de "bem viver"; ideia que ninguém aceita- 
ria que fosse definida unicamente em termos formais e abstratos.

A segunda tensão, por conseguinte, consiste na necessidade de que toda definição de dignidade humana possa ser relacionada claramente com aspectos concretos da própria vida humana. Não obstante, o risco que se corre por esse caminho é o de desfigurar a tal ponto a própria ideia de dignidade, de tal forma que ficaria reduzida a questões determinadas, pontuais, cotidianas e até irrelevantes (Monsalve; Román, 2009, p.45).

A tensão entre o caráter universal ou particular da dignidade concerne à fricção entre dois polos: de um lado, a existência de um valor absoluto e universal, inerente a todo ser humano em qualquer tempo e lugar; e, de outro, o caráter particular da dignidade, caracterizado por uma multiplicidade de várias dignidades, referente concretamente a grupos sociais cultural e historicamente determinados.

Com vistas a ultrapassar tais impasses, Gosdal (2006), apoiando-se em dois autores (Barcellona; Herrera Flores apud Gosdal, 2006), propõe o afastamento da interpretação naturalizada da dignidade, situando-a na concretude das relações de trabalho. Segundo a autora, o universal não é o ponto de partida, mas sim o de chegada.

É preciso criar condições para o desenvolvimento das potencialidades humanas, de um poder que se componha não de imposições e exclusões, mas de generalidades compartilhadas, às quais a sociedade chega e não das quais ela parte (2006, p.17).

Ainda na busca por superar as tensões conceituais presentes no conceito de dignidade fundante dos direitos humanos, a mesma contraposição entre direitos humanos e cidadania aparece entre direitos humanos e direitos fundamentais. Autores consideram que a expressão direitos humanos deveria ser reservada para os direitos positivados em normas internacionais, enquanto os direitos fundamentais remeteriam àqueles positivados no âmbito do direito interno dos Estados, contrapondo, assim, normas internacionais e ordenamento interno.

Sarlet $(2004,2011)$ corrobora essa conceituação ao distinguir direitos do homem, direitos huma- nos e direitos fundamentais. Direitos do homem seriam os direitos naturais ainda não positivados; direitos humanos seriam os positivados na esfera do direito internacional; e direitos fundamentais, os reconhecidos pelo direito constitucional interno de cada Estado.

Seguindo o argumento de Gosdal (2006), a autora propõe pensar a dignidade humana como historicamente construída e permanentemente reconstruída, e não como um direito próprio de uma natureza humana. Buscando romper com a dimensão essencialista do conceito, compreende que o significado de dignidade é determinado pela história e pelo trabalho de interpretação. Assim, a concepção atual dos direitos humanos (e o de dignidade) não é a mesma daquela que serviu de inspiração para a Declaração dos Direitos do Homem de 1948. E permanecerá sempre em transformação.

A questão que se coloca, no entanto, é o risco de um viés utilitarista do conceito de dignidade, que o inseriria em um raciocínio instrumental, perfeitamente adaptável à realidade do mercado e do modo de produção capitalista. O conceito perderia, assim, seu caráter de um direito necessário e essencial para tornar-se refém da lógica econômica, em que o bem-estar social coincide com o crescimento econômico, com a alta produtividade e com o incremento da técnica.

Assim, a dignidade necessita, simultaneamente, constituir-se como direito humano e direito fundamental:

Pela utilização que tem sido feita da dignidade e, ao mesmo tempo, pela necessidade de que seja observada nas relações entre os indivíduos, é preciso analisar se é norma, princípio, ou apenas valor fundante dos direitos fundamentais. $\mathrm{O}$ esclarecimento acerca da inserção da dignidade como direito fundamental, sem retirá-la do contexto dos direitos humanos, estando vinculada tanto aos tratados e convenções de direito internacional, como ao ordenamento jurídico interno, permite que se passe à consideração da dignidade não apenas como um princípio, de aplicabilidade duvidosa, mas também e, de maneira não excludente, como direito e necessidade. (Gosdal, 2006, p.38)

Uma concepção de dignidade que 
esteja subordinada à lógica das leis de mercado necessita, simultaneamente, considerar o ser humano concreto em sua dimensão individual e de pertencimento comunitário ou coletivo, suas diferenças, e ser dirigida à inclusão social. Não pode ser apenas compreendida como princípio (sob risco de tornar-se uma norma de aplicação duvidável); nem somente como valor fundante (o que poderia significar retirar-lhe a possibilidade de exigência de aplicabilidade, mas que deve permanecer como valor a ser mobilizado para legislar e julgar os direitos fundamentais).

A discussão sobre a dignidade, finalmente, encontra consenso (ou quase) na concepção formulada por Kant (Sarlet, 2004; Benevides, [1997?], Gosdal, 2006) de que o homem, como ser, não pode jamais ser considerado um meio para se alcançar um determinado fim, uma vez que ele já é um fim em si mesmo. Para Kant (2005), a dignidade se origina da autonomia ética do ser humano. A autonomia da vontade, como faculdade de autodeterminação e de ação em conformidade com certas leis, é um atributo que se encontra apenas nos seres racionais. Como um fim em si mesmo, o homem não pode ser usado como meio para atingir metas heterodoxas e fins estabelecidos para outros, não podendo, pois, ser coisificado ou instrumentalizado.

\section{TRABALHO DECENTE E TRABALHO DIGNO}

O trabalho decente estaria para a cidadania, assim como o trabalho digno estaria para os direitos humanos. Se, conceitualmente, a cidadania é um direito atrelado a uma determinada ordem jurídico-política (de um país, um Estado, no qual se define quem é cidadão e quais são seus direitos e deveres), os direitos humanos são universais e naturais, pois dizem respeito à dignidade da natureza humana (Benevides, [1997?]). Como já exposto, no intuito de relativizar - ou tornar menos absoluta - a noção essencialista da dignidade como natural, desenvolve-se uma noção de dignidade como meta a ser atingida, e não como ponto de partida.
No entanto, mesmo os autores que admitem a historicidade do conceito e de seu significado acabam integrando a dignidade como, simultaneamente, princípio, valor, direito e necessidade.

Admitamos uma concepção de dignidade como um conceito historicamente elaborado e culturalmente diferenciado. Se não é uma qualidade intrínseca à natureza humana, é, sim, um princípio e um valor que perpassa o direito, a política, a sociabilidade e se contrapõe abstratamente aos atos degradantes e "desumanos". Dada a tensão intransponível entre natureza e cultura, a fórmula kantiana de conceber o ser humano como um fim em si mesmo e jamais como um meio tem o mérito de apaziguar a discussão e permite partir-se de um princípio comum.

Dito isto, é mister colocar as indagações oriundas da noção de dignidade aplicadas às relações de trabalho. A tarefa torna-se ainda mais árdua. Se o homem não pode ser um meio de exploração de riquezas, como pensar o universo do trabalho? Como precisar as exigências de um trabalho digno ou de um trabalho decente?

É possível compreender-se que o salário mínimo, que constitui a remuneração de boa parte da população do país, garante as condições mínimas para uma vida saudável? Ou o conceito refere-se a um dever-ser abstrato, não à realidade concreta? E a possibilidade de pagamento do adicional de insalubridade em razão da existência de condições insalubres de trabalho? Não seria o caso de se proibir, então, qualquer trabalho em condições insalubres? Ou de se obrigar à melhoria das condições de trabalho, com a adoção de medidas de proteção coletiva dos trabalhadores, mesmo que tornando mais elevados os custos de produção? (Gosdal, 2006, p.98)

$$
\text { E ainda, }
$$

A dignidade do trabalhador preexiste ao vínculo contratual, constituindo direito atribuído genericamente aos cidadãos, que também são trabalhadores, convertendo-se em direito laboral em face dos sujeitos e da natureza da relação jurídica em que se faz valer (Gosdal, 2006, p.135).

A noção de trabalho decente hoje se encontra na agenda da OIT e, no Brasil, no Plano Nacional de Trabalho Decente, lançado em Brasília em 
2010 pelo Ministério do Trabalho e Emprego, conforme segue:

Trabalho Decente é uma condição fundamental para a superação da pobreza, a redução das desigualdades sociais, a garantia da governabilidade democrática e o desenvolvimento sustentável. Em inúmeras publicações, o Trabalho Decente é definido como o trabalho adequadamente remunerado, exercido em condições de liberdade, equidade e segurança, capaz de garantir uma vida digna. Para a Organização Internacional do Trabalho (OIT), a noção de trabalho decente se apoia em quatro pilares estratégicos: a) respeito às normas internacionais do trabalho, em especial aos princípios e direitos fundamentais do trabalho (liberdade sindical e reconhecimento efetivo do direito de negociação coletiva; eliminação de todas as formas de trabalho forçado; abolição efetiva do trabalho infantil; eliminação de todas as formas de discriminação em matéria de emprego e ocupação); b) promoção do emprego de qualidade; c) extensão da proteção social; d) diálogo social (Brasil, 2010, p.11).

É possível destacar, de maneira esquemática, que o trabalho decente é definido como o trabalho capaz de garantir uma vida digna. Mas pode o trabalho, como paradigma de luta, ser digno (em seu sentido moral de promover reconhecimento)? Como delimitar o que é digno? Ou o paradigma de luta possível de se estabelecer é que seja decente (seguro e de qualidade)? Só o trabalho decente viabiliza uma demanda concreta e operacional? Do ponto de vista da incidência da dignidade no contrato de trabalho e nas relações de trabalho, é preciso conciliar a dignidade moral com as questões como o trabalho justamente remunerado, prestado em condições de equidade e seguridade. Como afirma Gosdal (2006) a dignidade no trabalho é uma categoria axiológica aberta, que não pode ser fixada de modo definitivo, porque precisa ser permanentemente definida pelas situações concretas. Seu caráter histórico e dinâmico exige sua atualização constante. Mas não enfraquece os marcos teóricos dentro dos quais ela deve ser compreendida.

Segundo Mocellin (2009), o negativo de trabalho decente seria trabalho precário. Assim, o trabalho decente seria o contraponto à crescente insegurança e desproteção dos trabalhadores. É preciso elencar elementos que tornem o trabalho de- cente visível e quantificável e, assim, integrar a agenda dos diferentes organismos internacionais que lutam por maior justiça, equidade e proteção no mundo do trabalho. Para se tornar uma linha de ação, é preciso apresentar a noção do "bom trabalho", para que sirva de parâmetro.

Já um trabalho digno propõe, ao lado da noção de apropriado e adequado, também um sentido daquilo que tem ou revela dignidade ou honra. Ou seja, a dignidade acrescenta uma dimensão moral, apenas subentendida na noção de trabalho decente.

Se nem todo trabalho pode ser arte ou artesanato, dadas as condições de reprodução da sociedade capitalista, trabalho é aqui entendido como meio por excelência de inserção social nesta sociedade, conforme a noção defendida por Honneth (2008). Segundo o autor, o trabalho possui valor imanente no que se refere às formas de reconhecimento social. Dito de outro modo, contrariamente à perspectiva funcionalista do mercado capitalista do trabalho, segundo a qual ele se constitui de regramentos estratégicos das estruturas da organização capitalista e na qual o trabalho é meio por excelência do incremento da eficiência econômica, Honneth (2008) filia-se à perspectiva do mercado capitalista de trabalho com função de integração social. Segundo essa abordagem, afirma-se a existência de uma série de normas morais que subjazem ao mundo do trabalho, da mesma forma como as normas do agir orientado ao entendimento no mundo socialmente vivido. Essa seria a dimensão moral do trabalho, entendida como

[...] um pano de fundo valorativo que estabelece os bens imateriais e as noções do que é bom e do que é mau, e, consequentemente, do que é uma boa vida que deve ser valorizada por todos, o que pode gerar distinções e hierarquias (Maciel, 2006, p.319).

No intuito de transpor a dicotomia entre trabalho decente e trabalho digno, propomos duas abordagens complementares: 1) a inserção da noção de reconhecimento, sendo o trabalho o lócus teórico de reflexão sobre as formas de reconhecimento social; 2) a adoção de um modelo global de 
direitos humanos para a formulação de políticas, a regulação e a defesa do trabalho decente (Macnaughton; Frey, 2011).

\section{RECONHECIMENTOE DIGNIDADE}

Seguindo a discussão sobre trabalho decente e trabalho digno, é possível remeter ambos os conceitos, respectivamente, a um conteúdo de direitos mínimos e outro vinculado a uma dimensão moral independente de qualquer raciocínio de natureza econômica ou instrumental. Segundo Gosdal (2006), o trabalhador de qualquer matiz deve ter considerada a sua condição de pertencente à humanidade, de maneira que sejam reconhecidas, simultaneamente, sua autoria e participação na produção da riqueza social assim como as possibilidades de plena realização de seu potencial humano. A noção de reconhecimento parece ter um importante papel na articulação entre as duas dimensões, como se verá a seguir.

A teoria do reconhecimento tem como pressuposto de base a afirmação do outro. Honneth (2003) tem uma importante contribuição nesse sentido. O autor concebe reconhecimento como categoria moral abrangente e fundamental, enquanto trata da distribuição como derivativa. Afirma a existência de quatro premissas sobre o reconhecimento: 1) deve ser uma afirmação de qualidades positivas de sujeitos humanos ou de grupos; 2) deve ter as características de uma ação, ou seja, não pode se limitar a meras palavras ou expressões simbólicas, pois os comportamentos é que lhe darão credibilidade, o que é normativamente importante para o sujeito reconhecido; 3 ) deve ser a expressão de uma ação autônoma; 4) deve representar um conceito genérico que englobe diferentes variantes, como as atitudes do amor, do respeito jurídico e da estima social. Partindo dessas premissas, Honneth constrói uma tipologia dos padrões de reconhecimento intersubjetivo: na dimensão das relações primárias, as formas de reconhecimento são amor e amizade; na dimensão das relações jurídicas, são os direitos; na dimensão da comuni- dade de valor, é a solidariedade. Para o autor, devemos orientar uma ética política ou moralidade social pelos três princípios de reconhecimento (amor, igualdade jurídica e mérito) que, em nossas sociedades, governam aquelas expectativas legítimas de reconhecimento existentes entre os membros da sociedade.

\begin{abstract}
Afirma o autor,
Minha tese é que uma tentativa de renovar as reivindicações abrangentes da Teoria Crítica nas condições presentes faz melhor se orientar-se pelo quadro conceitual de uma teoria do reconhecimento suficientemente diferenciada, uma vez que ela estabelece uma ligação entre as causas sociais dos amplos sentimentos de injustiça e os objetivos normativos dos movimentos emancipatórios. Além disso, tal abordagem não corre o risco de introduzir um abismo irreversível entre aspectos ‘simbólicos' e 'materiais' da realidade social, uma vez que, nos pressupostos da teoria do reconhecimento, a relação entre os dois pode ser vista como resultado historicamente mutável de processos culturais de institucionalização (Honneth, 2003, p.113).
\end{abstract}

É possível, pois, inserir o trabalho, simultaneamente, na esfera do direito e da solidariedade social. A noção de reconhecimento é capaz de alçar o trabalho ao ponto de cruzamento entre as noções de cidadania e de dignidade, afeita, como já mencionado, à noção de direitos humanos. Nesse intuito, e baseando-se em Marshall (1965), Silva (2007) argumenta que a cidadania é propulsora da noção de igualdade social (enquanto o de classe social remeteria à desigualdade social). Afirma que a cidadania, ao mesmo tempo em que se contrapõe à lógica do mercado, geradora de desigualdade, funciona também como uma espécie de "religião civil" na garantia da unidade em meio à diversidade que caracteriza as sociedades modernas. Já em seu sentido moral, apoia-se em Taylor (1997), para quem o self possui duas dimensões: ontológica e histórica. A primeira diz respeito às características invariáveis de uma antropologia que independe do tempo e do espaço (pressupostos presentes em qualquer forma humana de sociabilidade), enquanto a segunda remete ao variável eà transformação. É visível o esforço de aproximar 
cidadania histórica à dignidade universal.

O trabalho remete, por um lado, ao instrumentalismo, à dominação e à submissão às forças de mercado, e por outro, à sociabilidade, à implicação moral, aos projetos pessoais e de estima social. No âmbito do trabalho e no capitalismo em especial, valores éticos e econômicos convivem em tensão permanente. Os indivíduos esperam por reconhecimento, simultaneamente, como humanos - e seria um reconhecimento incondicional - assim como por intermédio de sua performance e contribuição social - e seria um reconhecimento condicional (Taylor, 1997).

A noção de reconhecimento, em suas três esferas, teria a contribuição de articular, com vistas à justiça social, as esferas dos direitos e da solidariedade e contribuição social. Transpondo a contraposição entre cidadania e direitos humanos, o reconhecimento pelo trabalho integraria os sujeitos sociais às dimensões do direito e da comunidade moral de valores.

\section{UMA VISÃO HOLÍSTICA DOS DIREITOS HUMANOS}

$\mathrm{O}$ conceito de trabalho decente remete à noção de cidadania e direitos sociais. Possui indicadores objetivos e quantificáveis. Já o trabalho digno remeteria à noção de direitos humanos universais, à dimensão moral (avaliação do que é bom e do que é mau). O trabalho digno necessita do reconhecimento da contribuição e da utilidade do trabalho. É um trabalho que supõe autonomia. O trabalho digno se traduz em uma contribuição ao todo, é dotado de reconhecimento social e vem associado ao par contribuição e retribuição.

Segundo Macnaughton e Frey (2011), um modelo de direitos humanos que pretenda alcançar o trabalho decente compartilha, com o modelo de justiça social, as preocupações centrais da pobreza, da desigualdade e da dignidade humana. Embora haja uma variedade de modelos de direitos humanos, eles são todos derivados do quadro internacional de direitos humanos pela primeira vez expos- tas na DUDHe, posteriormente, implementados em vários tratados. As autoras advogam por um modelo holístico de direitos humanos, cuja ênfase está na unidade entre todos eles, contrariando a tendência de dividir os direitos humanos em categorias distintas. Esse modelo holístico sublinha a universalidade, a interdependência e a igualdade de todos os direitos humanos. Ele reconhece que todas as categorias de direitos humanos são essenciais à dignidade humana. No contexto do trabalho decente, a abordagem holística exige que todos os direitos humanos devam ser considerados. Por exemplo, para combater o trabalho infantil, os decisores políticos devem considerar, para além de uma idade mínima para o emprego, o direito da criança à educação, saúde, vida familiar e participação na comunidade, entre outros direitos que podem ser afetados por essa mudança de política.

Esta visão holista, proposta pelas autoras, pressupõeinterdependência, inter-relação, indivisibilidade dos direitos, ou seja, os direitos humanos estão inter-relacionados no sentido de que eles estão intrinsecamente ligados uns aos outros. Assim, são interdependentes em dois sentidos, refletindo: a) as relações entre direitos, e b) as relações entre as pessoas. E são indivisíveis no sentido de que os direitos formam uma estrutura una na qual o valor de cada direito é significativamente aumentado pela presença dos demais. Já os quatro pilares da OIT sobre o Trabalho Decente necessitariam ser estendidos à defesa do trabalho decente através da adoção de um modelo global de direitos humanos. Assim, o direito humano ao trabalho decente pode ser compreendido de maneira ampla e integrando vários componentes fora do âmbito do Núcleo de Normas Trabalhistas da OIT. De suma importância, os pilares da OIT devem ser abordados e exigidos concretamente, mas também devem ser inseridos em uma teia de interdependência com os direitos humanos que remetam à dignidade. Um modelo de direitos humanos comprometido com o trabalho decente implica um modelo de justiça social no qual as questões relativas à pobreza, desigualdade e dignidade humana são incontornáveis. Para isso, terá de reconhecer que as diversas dimensões da vida 
das pessoas estão interligadas, são interdependentes e indivisíveis, e, consequentemente, devem ser abordadas no quadro dos direitos humanos em uma visão integral.

As autoras sugerem algumas estratégias para atingir um modelo global de direitos humanos: a) a definição do trabalho decente de uma forma holística, b) o reconhecimento da interdependência de todos os direitos humanos na regulação do trabalho decente, c) a aplicação de métodos baseados nos direitos humanos e de suas ferramentas para a formulação de políticas, e d) coalizões em torno de interesses comuns, vinculando o direito ao trabalho decente com outros direitos (Macnaughton; Frey, 2011, p.8).

\section{CONSIDERAÇÕES FINAIS}

Trabalho decente e trabalho digno inseremse na interdependência inerente ao conjunto de direitos humanos. Ambos se enquadram em um modelo integral de justiça social, sendo que o primeiro remete à operacionalidade dos direitos e o segundo, à comunidade de valores morais.

O trabalho é aqui compreendido como contribuição ao bem geral: o trabalho seria lócus da integração do indivíduo ao todo social e não somente meio de suprir necessidades, articulando-se a abordagem do trabalho entendida como integração sistêmica (produtividade) com a do trabalho como forma de integração social (dependente de princípios morais). Honneth (2008) desenvolve o argumento de que o trabalho tem valor imanente no que se refere às formas de reconhecimento social.

O trabalho integra, concomitantemente, as esferas do direito e da solidariedade social. Entendido no âmbito das formas sociais de reconhecimento, o trabalho decente permite a configuração de um modelo de direitos a serem respeitados, enquanto o trabalho digno remete aos valores e à moral. Essa articulação configura um modelo integral e holístico de direitos humanos, no qual todos os direitos são universais, interdependentes e iguais em importância.

A noção de reconhecimento social do traba- lho e a dimensão integral dos direitos humanos permitem transpor teoricamente a contraposição entre trabalho digno e trabalho decente, entre direitos humanos e cidadania.

(Recebido para publicação em 19 de setembro de 2011) (Aceito em 11 de março de 2012)

\section{REFERÊNCIAS}

ABRAMOVICH, V. Linhas de trabalho em direitos econômicos, sociais e culturais: instrumentos e aliados. Revista SUR - Revista Internacional de Direitos Humanos, São Paulo, n.2, 2006, p.189-223. Disponível em: Hiperlink, www.surjournal. org/index2.php ; www.surjournal.org/ index2.php. Acesso em: 23 out. 2010.

BENEVIDES, M. Cidadania e direitos humanos. Instituto de Estudos Avançados, São Paulo, USP, v.11, n.30, [1997?] Disponível em: Hiperlink, www.iea. usp.br/artigos. Acesso em: 10 abr. 2010.

BRASIL. Ministério do Trabalho e Emprego. Plano Nacional de Trabalho Decente. Brasília, 2010. Disponível em: Hiperlink, www.mte.gov.br/antd/programa_nacional.asp. Acesso em: 02 dez. 2010.

COSTA, C.; ARANTES, R. Direito humano ao trabalho. Curitiba: Ed. Ines, 2009. (Coleção cartilhas de direitos humanos, v.5).

GOSDAL, T. C. Dignidade do trabalhador: um conceito construído sob o paradigma do trabalho decente e da honra. 2006. 195f. Tese (Doutorado em Direito) - Programa de ra. 2006. 195f. Tese (Doutorado em Direito) - Programa de Curitiba, 2006. Disponível em: Hiperlink, http:// dspace.c3sl.ufpr.br/dspace/bitstream/handle/1884/4675/ THEREZA \%20CRISTINA20GOSDAL.PDF;jsessionid= F7574BEF17D81611DD6688EE7671C2AC?sequence= Acesso em: 01 jun. 2011.

HONNETH, A. Redistribution as recognition: a response to Nancy Fraser. In: FRASER, Nancy.; HONNETH, A Redistribution or recognition; a political-philosophical exchange. London; New York: Verso, 2003.

Trabalho e reconhecimento; Tentativa de uma redefinição. Civitas - Revista de Ciências Sociais, Porto Alegre, PUCRS, v.8, n.1, jan./abr. 2008.

KANT, I. Fundamentação da metafísica dos costumes e outros escritos. São Paulo : Martin Claret, 2005.

LE DROIT au travail. Observation générale $n^{\circ} 18 / 2005$, Article 6 du Pacte international relatif aux droits économiques, sociaux et culturels. Disponível em: Hiperlink, http://www2.ohchr.org/english/bodies/cescr/ comments.htm. Acesso em: 30 maio 2011.

MACIEL, Fabrício. Todo trabalho é digno?: um ensaio sobre moralidade e reconhecimento na modernidade periférica. In: SOUZA, J. (Org.) A invisibilidade da desigualdade brasileira. Belo Horizonte: UFMG, 2006.

MACNAUGHTON, G.; FREY, D. F. Decent work for all: a holistic human rights approach. American University International Law Review, Washington, DC, v.26, p.414483, 2011.Disponível em: Hiperlink, http:// papers.ssrn.com/s ol $3 /$ papers.cfm? abstract id=1614282"|l”\#"; http://ssrn.com/abstract=1614282; Âcesso em: 01 set. 2011. 
MARSHALL, T. H. Class, citizenship, and social development. Garden City: Anchor Books, 1965.

MOCELIN, Daniel Gustavo. Do trabalho precário ao trabalho decente? A qualidade do emprego como perspectiva analítica. In: CONGRESSO DA ASSOCIAÇÃO DE ESTU DOS LATINO-AMERICANOS LASA,28. Rio de Janeiro, 2009. Anais..

MONSALVE, V.; ROMÁN, J. As tensões da dignidade humana: conceituação e aplicacão no direito internacional dos direitos humanos. Revista SUR - Revista Internacional de Direitos Humanos, São Paulo, v.6, n.11, dez. p.41 63, 2009. Disponível em: Hiperlink, www.surjournal.org/ index11.php. Acesso em: 12 mar. 2011.

ORGANIZAĈ̃O INTERNACIONAL DO TRABALHO OIT. Constituição da Organização Internacional do Trabalho e seu Anexo (Convenção de Filadélfia -1944). Disponível em: Hiperlink, www.oitbrasil.org.br/sites/default/ files/topic/ decent work/doc/constituição oit 538.pdf; www.oitbrasil.org.br/info/download/ constituicao oit. pdf. Acesso em: 25 maio 2011.

Declaração sobre Princípios e Direitos Fundamentais no Trabalho da OIT - 1998. Disponível em: Hiperlink, www.oitbrasil.org.br/info/download/ declarac_port.pdf ; Acesso em: 20 maio 2011.

ORGANIZAÇÃO DAS NACÕES UNIDAS - ONU. Declaração e Programa de Ação de Viena. Genebra: ONU, 1993. (A/CONF 157/23). Disponível em: Hiperlink, www.pge.sp.gov.br/centrodeestudos/bibliotecavirtual/instrumentos/viena.htm. Acesso em: 20 out. 2010.
PIOVESAN, F. Direitos humanos globais, justiça internacional e o Brasil. Revista Fundação Escola Superior do Ministério Público, Brasília, v.8, n.15, p.93-110, jan./jun. 2000. Disponível em: Hiperlink, www.escolamp.org.br/ ARQUIVOS/15_07.pdf. Acesso em: 23 mar. 2011.

SARLET, I. W. Dignidade da pessoa humana e direitos fundamentais. Porto Alegre: Livraria do Advogado, 2011

A eficácia dos direitos fundamentais. 4.ed. Porto Alegre: Livraria do Advogado, 2004.

SILVA, J. Trabalho, cidadania e reconhecimento. São Paulo: AnnaBlume, 2007.

TAYLOR, C. As fontes do self; a construção da identidade moderna. São Paulo: Loyola, 1997.

WEB SITE da Biblioteca Virtual de Direitos Humanos da USP. Disponível em: Hiperlink, www.direitoshumanos. usp.br/ Acesso em: 20.05.2011.

WEB SITE da Organização Internacional do Trabalho. Disponível em: Hiperlink, www.ilo. org. Acesso em: 20.05.2011.

WEB SITE do Comitê de Direitos Econômicos, Sociais e Culturais da ONU: Disponível em: Hiperlink, http:// www2.ohchr.org/english/bodies/cescr/comments.htm. Acesso em: 20.05.2011. 


\section{THE DICHTOMY BETWEEN DECENT LABOR AND WORTHY LABOR AND BEYOND: recognition and human rights}

\author{
Cinara L. Rosenfield \\ Jandir Pauli
}

This paper aims at enabling a theoreticalconceptual discussion about the concepts of decent labor and worthy labor, from the conceptual contraposition between citizenship and human rights. Its argument is that decent labor would refer to the basic idea of citizenship and to an operational concept, clearly pointed out in the order of the day of the International Labor Organization (ILO), whereas worthy labor would refer to the Universal Declaration of Human Rights (UDHR), depending on a network of rights. In order to transpose this dichotomy, we propose a complete overview of human beings at work, based on the concept of recognition and the holistic approach of human rights, which form the basic idea of decent labor.

KEY wORDS: decent labor, worthy labor, human rights, holistic vision of rights, recognition.

\section{AU-DELÀ DE LA DICHOTOMIE ENTRE TRAVAIL DECENT ET TRAVAIL DIGNE: la reconnaissance et les droits de l'homme}

\author{
Cinara L. Rosenfield \\ Jandir Pauli
}

Le but de cette étude est de discuter des notions théoriques et conceptuelles du travail décent et du travail digne en partant de l'opposition entre le concept de citoyenneté et celui des droits de l'homme. L'argument de base est que le travail décent se rapporte à la notion de citoyenneté et à un concept opérationnel clairement définis par l'Organisation Internationale du Travail (OIT), alors que le travail digne se rapporte à la Déclaration Universelle des Droits de l'Homme (DUDH) et dépend de tout un réseau de droits. Afin de dépasser cette dichotomie, nous proposons d'avoir une perception intégrale de l'être humain au travail dans une conception de reconnaissance et d'approche holistique des droits de l'homme dont la notion de travail décent fait partie.

Mots-CLÉs: travail décent, travail digne, droits de l'homme, vision complète des droits, reconnaissance.

Cinara L. Rosenfield - Doutora em Sociologia do Trabalho e Pós-Doutorado pela Universidade Técnica de Lisboa. Professora do Departamento de Sociologia e do Programa de Pós-Graduação de Sociologia, IFCH, UFRGS. Bolsista Produtividade CNPQ. A Sociologia do Trabalho é a sua área de interesse principal. Dentre as suas publicações recentes destacam-se: Trabalho decente e precarização. Tempo Social, São Paulo, USP, 2011; Autonomia e trabalho informacional: o teletrabalho. Dados, Rio de Janeiro, 2011; Trabalho, emprego e precarização social. Sociologias, Porto Alegre, UFRGS, 2010; L'autonomie comme norme et le rapport au travail: une étude comparative France-Brésil. Saarbrücken: Éditions Universitaires Européennes, 2010.

JandirPauli - Doutor em Sociologia. Professor da Faculdade Meridional (IMED). Como pesquisador, atua nas linhas de pesquisas: Trabalho na sociedade contemporâneas e Estratégias e Relações Interorganizacionais. Pesquisador do RILESS: Red de Investigadores Latinoamericanos de Economía Social y Solidária. Dentre as suas publicações destacam-se: Economia política do trabalho e direitos humanos. Passo Fundo: IMED Editora, 2008; Estratégias individuais e ordens de justiça no capitalismo conexionista. In: Congresso Brasileiro de Sociologia, 14, Rio de Janeiro: SBS, 2009. 